SCIENTIFIC REPORT

\title{
Response of choroidal blood flow to carbogen breathing in smokers and non-smokers
}

\author{
B Wimpissinger, H Resch, F Berisha, G Weigert, L Schmetterer, K Polak
}

Br J Ophthalmol 2004;88:776-781. doi: 10.1136/bjo.2003.031773

\begin{abstract}
Aim: To investigate a potential difference in ocular vascular reactivity during carbogen breathing in optic nerve head, choroid, and retina between healthy smokers and nonsmokers.

Methods: 25 (13 smokers and 12 non-smokers) healthy male volunteers participated in this observer masked, two cohort study. During inhalation of carbogen $\left(5 \% \mathrm{CO}_{2}\right.$ and $\left.95 \% \mathrm{O}_{2}\right)$ over 10 minutes measurements were taken using laser Doppler flowmetry to assess submacular choroidal and optic nerve head blood flow, laser interferometry to assess fundus pulsation amplitudes, and retinal vessel analyser (RVA) to assess retinal vessel diameters.

Results: At baseline choroidal blood flow was higher $(p=0.018$, ANOVA) in smokers than in non-smokers. During administration of carbogen the response in choroidal blood flow was significantly different between the two groups: there was an increase in non-smokers after carbogen breathing $(p=0.048)$ compared with relatively stable blood flow in smokers ( $p=0.049$ between groups, ANOVA). A similar response pattern was seen for fundus pulsation amplitude, which increased notably after carbogen breathing in non-smokers but not in smokers $(p<0.001$ between groups, ANOVA). Optic nerve head blood flow and retinal vessel diameters were reduced in both groups to a comparable degree during carbogen breathing.

Conclusion: The study indicated abnormal choroidal vascular reactivity in chronic smokers. These early haemodynamic changes may be related to the increased risk to smokers of developing ocular vascular diseases. The specific mechanisms underlying abnormal choroidal vascular reactivity in chronic smokers remain to be characterised.
\end{abstract}

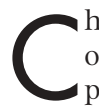
hronic smoking is known to be a risk factor for a variety of ocular vascular diseases like hypertensive retinopathy, age related macular degeneration, and anterior ischaemic optic neuropathy. ${ }^{1}$ The exact pathomechanisms linking smoking to ocular vascular disease are not fully understood. Animal studies showed that chronic smoking causes a significant increase of choroidal vascular resistance. ${ }^{2}$ In humans, one study found higher blood flow velocities in the ophthalmic artery, the central retinal artery, and the posterior ciliary arteries in chronic smokers by means of a colour Doppler device. ${ }^{3}$ In contrast, two other studies describe decreased blood flow velocities in these vessels due to chronic smoking also using a colour duplex imaging system. ${ }^{45}$ Acute cigarette smoking, on the other hand, was reported to induce a decrease of blood velocity in the optic nerve head and possibly in the choroid by the means of the laser speckle method, suggesting an increase in vascular resistance. ${ }^{6}$

In a previous study using the 133Xe inhalation method, chronic cigarette smoking reduced the cerebrovascular responsiveness to $5 \% \mathrm{CO}_{2}$ and $100 \% \mathrm{O}_{2}{ }^{7}$ indicating that chronic cigarette smokers have both reduced vasodilator and reduced vasoconstrictor capacity when compared with nonsmokers. It is, however, not known whether such a difference also holds true for the ocular circulation.

The present study set out to investigate a potential difference in vascular reactivity of optic nerve head, choroid, and retina during carbogen breathing between healthy smokers and non-smokers.

\section{PATIENTS AND METHODS \\ Subjects}

The present study was performed in adherence to the Declaration of Helsinki and the Good Clinical Practice guidelines. After approval of the study protocol by the ethics committee of the Vienna University School of Medicine and after written informed consent was obtained, 25 healthy male volunteers were enrolled in the study (mean age 25 (SD 3) years, range 19-35). Thirteen participants had been smokers for at least two years and regularly smoked between 15 and 25 cigarettes per day. The other 12 volunteers had no history of smoking. All volunteers were drug free for at least 3 weeks before inclusion and passed a prestudy screening during the 4 weeks before the first study day, which included physical examination and medical history, 12 lead electrocardiogram, blood and urine analysis, random urine drug screen, and ophthalmic examination. Subjects were excluded if any clinically relevant abnormality was found as part of the pretreatment screening. In addition, subjects with ametropia of more than 3 diopters, anisometropia more than 1 diopter, or any evidence of eye disease that might interfere with the purpose of the present trial were excluded.

To objectively distinguish between smokers and nonsmokers, it was necessary to determine the level of cotinine in urine. Cotinine, the major metabolite of nicotine, has a half life of 24 hours and is readily detectable in the smoker's urine even several days after the smoker has terminated smoking. This investigation was done with a homogenous immunoassay (EMIT-technique, Diagnostic Reagents Inc, Sunnyvale, CA, USA). ${ }^{8}$ Sensitivity of this test, defined as the lowest concentration detectable, is $50 \mathrm{ng} / \mathrm{mL}$. Moreover, no significant cross reactivities to other substances exist. In addition, the subjects were asked to complete the Fagerstrom tolerance questionnaire. ${ }^{9}$ This questionnaire shows a significant correlation with daily cigarette consumption. ${ }^{10}$

\section{Experimental design}

This study followed an observer masked design in two cohorts. Subjects were asked to refrain from alcohol and caffeine for at least 12 hours before trial days. Moreover they

Abbreviations: DBP, diastolic blood pressure; FPA, fundus pulsation amplitude; LDF, laser Doppler flowmetry; MAP, mean arterial blood pressure; $\mathrm{ONH}$, optic nerve head; $\mathrm{PR}$, pulse rate; $\mathrm{RBC}$, red blood cell; RVA, retinal vessel analyser; SBP, systolic blood pressure. 
were asked to desist from smoking for at least 2 hours before measurements to rule out acute effects of cigarette smoking. Dilatation of one pupil was obtained with tropicamide (Mydriaticum "Agepha" Augentropfen, AGEPHA GmbH, Vienna, Austria).

The actual time schedule of the study day is presented in table 1 . After a 20 minute resting period in a sitting position, baseline measurements of fundus pulsation amplitude were obtained during breathing of room air. Stable baseline conditions were established and ensured by repeated measurements of blood pressure. Thereafter baseline measurements of choroidal blood flow with laser Doppler flowmetry were done for 2 minutes. The laser Doppler measurements were continued without cessation during breathing of carbogen (Oxymix 5\%, AGA, Vienna, Austria (certified gases for human use)) over a period of 10 minutes. Immediately after cessation of the laser Doppler measurements another measurement of fundus pulsation amplitude was done when gas delivery was still on. The gas was delivered through a partially expanded reservoir bag at atmospheric pressure using a two valve system to prevent rebreathing. Thereafter a minimum time span of 30 minutes was scheduled to re-establish baseline conditions. Two more carbogen breathing periods followed. Measurements were now done with laser Doppler flowmetry in the optic nerve head (period 2) and with the Zeiss retinal vessel analyser (period 3) following the time schedule as described above. Blood gas analysis and laser interferometry were done at baseline and at the end of the first breathing period. The time span between two subsequent breathing periods was at least 30 minutes.

\section{Systemic haemodynamics}

Systolic, diastolic, and mean arterial blood pressure (SBP, DBP, and MAP) were measured on the upper arm by an automated oscillometric device. Pulse rate (PR) was automatically recorded from a finger pulse oximeter (HP-CMS patient monitor; Hewlett-Packard, Palo Alto, CA, USA). Systemic haemodynamics were measured in 2 minute intervals during carbogen breathing periods and in 10 minute intervals during resting periods. Pulse rate and a real time ECG were monitored continuously.

\section{Laser Doppler flowmetry}

Continuous measurements of laser Doppler flowmetry (LDF) choroidal blood flow parameters (ChBVel, ChBVol, and ChBF) were performed. ${ }^{11}$ A commercially available fundus camera based system was used (Oculix 4000, Oculix Sarl, Arbaz, Switzerland). With this technique, the vascularised tissue is illuminated by coherent laser light, and light scattered by the moving red blood cells (RBCs) undergoes a frequency shift. Based on a model of light scattering in tissue $^{12}$ the following flow parameters are calculated: mean RBCs velocity in $\mathrm{Hz}$, blood volume, and blood flow in arbitrary units. All these flow parameters were then averaged over periods of two minutes.

In the present study laser Doppler flowmetry was performed in the fovea to assess choroidal blood flow, ${ }^{11}$ and at the neuroretinal rim to assess optic disc blood flow.

\section{Fundus pulsation measurement with laser interferometry}

Pulse synchronous pulsations of the eye fundus were assessed by laser interferometry. The method is described in detail by Schmetterer et al. ${ }^{13}$ Briefly, the eye is illuminated by the beam of a single mode laser diode along the optical axis. The light is reflected at both the front side of the cornea and the retina. The two remitted waves produce interference fringes from which the distance changes between cornea and retina during a cardiac cycle can be evaluated. The fundus pulsation amplitude (FPA), which is the maximum distance change between cornea and retina during the cardiac cycle, has been shown to estimate pulsatile blood flow in the choroid. ${ }^{14}$ Measurements were performed in the fovea to assess pulsatile choroidal blood flow.

\section{Zeiss retinal vessel analyser}

Retinal vessel diameters were determined from retinal images recorded with a fundus camera based system. The Zeiss retinal vessel analyser (RVA) is a commercially available system which comprises a fundus camera (Zeiss FF 450, Jena, Germany), a video camera, a real time monitor, and a personal computer with an analysing software for the accurate determination of retinal arterial and venous diameters. ${ }^{15}$ For this purpose the fundus is imaged onto the charge coupled device chip of the video camera. Because of the absorbing properties of haemoglobin each blood vessel has a specific transmittance profile. The consecutive fundus images are digitised using a frame grabber. In addition, the fundus image can be inspected on the real time monitor. Evaluation of the retinal arterial diameters was done online, and of venous diameters offline from the recorded video tapes. Our previous data showed excellent reproducibility with the Zeiss retinal vessel analyser. ${ }^{16}$

\section{Blood gas analysis}

Blood gas values were determined from capillary blood samples of the earlobe. After applying an ointment (Finalgon, Thomae, Biberach, Germany) locally to the earlobe to induce capillary vasodilatation, a lancet incision was made. The arterialised blood was drawn into a thin glass capillary tube. Arterial oxygen tension $\left(\mathrm{pO}_{2}\right)$, carbon dioxide tension $\left(\mathrm{pCO}_{2}\right)$, and oxygen saturation $\left(\mathrm{SaO}_{2}\right)$ were determined with an automatic blood gas analysis system (AVL $995 \mathrm{Hb}$, Graz, Austria).

\begin{tabular}{|c|c|c|c|c|c|}
\hline $\begin{array}{l}\text { At least } \\
30 \text { minutes }\end{array}$ & $\downarrow$ & 2 minutes & $\downarrow$ & 10 minutes & $\downarrow$ \\
\hline Resting period & $\begin{array}{l}\text { Fundus } \\
\text { pulsation } \\
\text { measurement }\end{array}$ & $\begin{array}{l}\text { Baseline measurements } \\
\text { with LDF in the macula }\end{array}$ & $\begin{array}{l}\text { Start of } \\
\text { carbogen } \\
\text { breathing }\end{array}$ & $\begin{array}{l}\text { LDF measurement in the } \\
\text { macula during breathing } \\
\text { of carbogen }\end{array}$ & $\begin{array}{l}\text { Fundus } \\
\text { pulsation } \\
\text { measurement }\end{array}$ \\
\hline Resting period & & $\begin{array}{l}\text { Baseline measurements } \\
\text { with LDF in the optic } \\
\text { nerve head }\end{array}$ & & $\begin{array}{l}\text { LDF measurement in the } \\
\text { optic nerve head during } \\
\text { breathing of carbogen }\end{array}$ & \\
\hline Resting period & & $\begin{array}{l}\text { Baseline measurements } \\
\text { with the Zeiss retinal } \\
\text { vessel analyser }\end{array}$ & & $\begin{array}{l}\text { Retinal vessel diameter } \\
\text { measurement during } \\
\text { breathing of carbogen }\end{array}$ & \\
\hline
\end{tabular}




\section{DATA ANALYSIS}

Statistical analysis was done with Statistica for Windows (Statsoft Inc (1997), Tulsa, OK, USA). All outcome parameters were averaged over periods of 2 minutes. Effects of carbogen breathing on haemodynamic parameters were analysed by $t$ test and repeated measure ANOVA. A p value of $<0.05$ was considered the level of significance. For data description, relative values are given as mean (SEM).

\section{RESULTS}

The results of the Fagerstrom Tolerance Questionnaire were 0 (0) points for the non-smoking group and $4.0(0.6)$ points for the smoking group, indicating nicotine dependence among the smokers. Cotinine levels in urine were 45.1 (11.5) ng/ml in non-smokers and 2025.7 (336.1) ng/ml in smokers. This again clearly indicates that the smokers were adequately selected, because the urine cotinine concentration in nonsmokers is normally below $500 \mathrm{ng} / \mathrm{ml} .^{17}$

At baseline (table 2 ) a significantly lower diastolic blood pressure ( $p=0.041$, ANOVA) was seen in non-smokers as compared with smokers. In addition, a lower choroidal blood cell volume ( $p=0.026$, ANOVA) as well as a lower choroidal blood flow $(p=0.018$, ANOVA) were observed in nonsmokers. No significant differences in $\mathrm{pO}_{2}, \mathrm{pCO}_{2}$, or $\mathrm{SaO}_{2}$ were observed between smokers and non-smokers at baseline conditions.

The effects of 10 minutes of breathing carbogen on systemic and ocular haemodynamic parameters are presented in table 3. Administration of carbogen significantly increased systolic blood pressure (+6.0 (1.5)\%, p $=0.002 v$ baseline) and mean arterial pressure $(+4.1(1.6) \%, \mathrm{p}=0.024 v$ baseline $)$ in smokers but not in non-smokers. This change in systolic and mean blood pressure was, however, not significantly different between the two groups. Diastolic blood pressure and pulse rate remained unchanged during carbogen breathing in both groups.

During administration of carbogen choroidal blood cell volume tended to decrease in smokers whereas it increased in

Table 2 Baseline values of ocular and systemic haemodynamic parameters and blood gas values

\begin{tabular}{|c|c|c|c|}
\hline Parameters & Smokers & Non-smokers & $\begin{array}{l}\text { p Value } \\
\text { (ANOVA) }\end{array}$ \\
\hline $\mathrm{SBP}(\mathrm{mm} \mathrm{Hg})$ & $118(3)^{*}$ & $117(3)$ & 0.845 \\
\hline $\mathrm{DBP}(\mathrm{mm} \mathrm{Hg})$ & 67 (3) & $56(4)$ & 0.041 \\
\hline MAP (mm Hg) & 85 (3) & 76 (3) & 0.058 \\
\hline PR (beats/min) & $71(2.0)$ & $69(3.0)$ & 0.553 \\
\hline $\begin{array}{l}\text { Choroidal red blood cell } \\
\text { velocity (AU) }\end{array}$ & $0.46(0.02)$ & $0.47(0.02)$ & 0.763 \\
\hline $\begin{array}{l}\text { Choroidal red blood cell } \\
\text { volume (AU) }\end{array}$ & $0.29(0.03)$ & $0.21(0.02)$ & 0.026 \\
\hline Choroidal blood flow (AU) & $11.8(1.0)$ & $8.6(0.8)$ & 0.018 \\
\hline $\begin{array}{l}\text { ONH red blood cell velocity } \\
\text { (AU) }\end{array}$ & y $0.35(0.02)$ & $0.33(0.02)$ & 0.510 \\
\hline $\begin{array}{l}\text { ONH red blood cell volume } \\
\text { (AU) }\end{array}$ & $0.30(0.04)$ & $0.25(0.03)$ & 0.371 \\
\hline ONH blood flow (AU) & $9.1(1.0)$ & $7.1(0.7)$ & 0.149 \\
\hline $\begin{array}{l}\text { Arterial retinal diameter } \\
(\mu \mathrm{m})\end{array}$ & $125.8(4.7)$ & $125.2(4.0)$ & 0.924 \\
\hline $\begin{array}{l}\text { Venous retinal diameter } \\
(\mu \mathrm{m})\end{array}$ & $158.8(4.5)$ & $139.5(3.9)$ & 0.091 \\
\hline $\begin{array}{l}\text { Fundus pulsation amplitude } \\
(\mu \mathrm{m})\end{array}$ & $3.6(0.3)$ & $3.8(0.2)$ & 0.713 \\
\hline $\mathrm{PO}_{2}(\mathrm{~mm} \mathrm{Hg})$ & $83.4(2.2)$ & $83.9(1.1)$ & 0.824 \\
\hline $\mathrm{PCO}_{2}(\mathrm{~mm} \mathrm{Hg})$ & $41.1(1.0)$ & $42.1(0.9)$ & 0.438 \\
\hline $\mathrm{SaO}_{2}(\%)$ & $95.6(0.4)$ & $95.9(0.2)$ & 0.603 \\
\hline
\end{tabular}

SBP, systolic blood pressure; DBP, diastolic blood pressure; MAP, mean arterial pressure; $P R$, pulse rate; $A U$, arbitrary units; $\mathrm{ONH}$, optic nerve head.

*Data are presented as mean (SEM).
Table 3 Effects of 10 minutes of breathing of carbogen on systemic and ocular haemodynamic parameters (\% change from baseline, $t$ test, post hoc testing) and significant differences between the two groups (ANOVA)

\begin{tabular}{|c|c|c|c|}
\hline Parameters & Smokers (\%) & Non-smokers (\%) & $\begin{array}{l}\text { p Value } \\
\text { (ANOVA) }\end{array}$ \\
\hline $\mathrm{SBP}(\mathrm{mm} \mathrm{Hg})$ & $\begin{array}{l}+6.0(1.5)^{*} \\
p=0.002\end{array}$ & $\begin{array}{l}+0.8(2.5) \\
p=0.75\end{array}$ & 0.187 \\
\hline $\mathrm{DBP}(\mathrm{mm} \mathrm{Hg})$ & $\begin{array}{l}+3.9(3.0) \\
p=0.217\end{array}$ & $\begin{array}{l}+26.2(17.9) \\
p=0.174\end{array}$ & 0.251 \\
\hline MAP $(\mathrm{mm} \mathrm{Hg})$ & $\begin{array}{l}+4.1(1.6) \\
p=0.024\end{array}$ & $\begin{array}{l}+8.8(4.2) \\
p=0.063\end{array}$ & 0.667 \\
\hline PR (beats/min) & $\begin{array}{l}-3.1(1.5) \\
p=0.067\end{array}$ & $\begin{array}{l}+0.7(2.8) \\
p=0.793\end{array}$ & 0.919 \\
\hline $\begin{array}{l}\text { Choroidal red blood } \\
\text { cell velocity (AU) }\end{array}$ & $\begin{array}{l}+2.9(1.5) \\
p=0.079\end{array}$ & $\begin{array}{l}+1.9(2.5) \\
p=0.469\end{array}$ & 0.675 \\
\hline $\begin{array}{l}\text { Choroidal red blood } \\
\text { cell volume (AU) }\end{array}$ & $\begin{array}{l}-9.1(5.2) \\
p=0.103\end{array}$ & $\begin{array}{l}+6.3(4.7) \\
p=0.203\end{array}$ & 0.032 \\
\hline $\begin{array}{l}\text { Choroidal blood flow } \\
\text { (AU) }\end{array}$ & $\begin{array}{l}-5.7(5.0) \\
p=0.269\end{array}$ & $\begin{array}{l}+8.0(3.6) \\
p=0.048\end{array}$ & 0.049 \\
\hline $\begin{array}{l}\text { ONH red blood cell } \\
\text { velocity (AU) }\end{array}$ & $\begin{array}{l}-5.2(4.3) \\
p=0.246\end{array}$ & $\begin{array}{l}-7.9(5.1) \\
p=0.154\end{array}$ & 0.734 \\
\hline $\begin{array}{l}\text { ONH red blood cell } \\
\text { volume (AU) }\end{array}$ & $\begin{array}{l}-15.3(5.0) \\
p=0.01\end{array}$ & $\begin{array}{l}-10.5(8.3) \\
p=0.237\end{array}$ & 0.282 \\
\hline ONH blood flow (AU) & $\begin{array}{l}-20.2(5.4) \\
p=0.003\end{array}$ & $\begin{array}{l}-21.3(5.1) \\
p=0.002\end{array}$ & 0.934 \\
\hline $\begin{array}{l}\text { Arterial retinal } \\
\text { diameter }(\mu \mathrm{m})\end{array}$ & $\begin{array}{l}-5.6(1.6) \\
p=0.001\end{array}$ & $\begin{array}{l}-5.3(1.7) \\
p=0.013\end{array}$ & 0.959 \\
\hline $\begin{array}{l}\text { Venous retinal } \\
\text { diameter }(\mu \mathrm{m})\end{array}$ & $\begin{array}{l}-14.7(1.4) \\
\mathbf{p}<0.001\end{array}$ & $\begin{array}{l}-11.0(1.3) \\
\mathbf{p}<0.001\end{array}$ & 0.104 \\
\hline $\begin{array}{l}\text { Fundus pulsation } \\
\text { amplitude }(\mu \mathrm{m})\end{array}$ & $\begin{array}{l}-2.5(3.3) \\
p=0.46\end{array}$ & $\begin{array}{l}+18.1(2.0) \\
\mathbf{p}<0.001\end{array}$ & $<0.001$ \\
\hline $\mathrm{PO}_{2}(\mathrm{~mm} \mathrm{Hg})$ & $\begin{array}{l}+241.5(36.0) \\
\mathbf{p}<0.001\end{array}$ & $\begin{array}{l}+255.0(19.0) \\
\mathbf{p}<0.001\end{array}$ & 0.737 \\
\hline $\mathrm{PCO}_{2}(\mathrm{~mm} \mathrm{Hg})$ & $\begin{array}{l}+14.8(2.6) \\
\mathbf{p}<0.001\end{array}$ & $\begin{array}{l}+10.2(2.0) \\
\mathbf{p}<0.001\end{array}$ & 0.149 \\
\hline $\mathrm{SaO}_{2}(\%)$ & $\begin{array}{l}+4.3(0.1) \\
\mathbf{p}<0.001\end{array}$ & $\begin{array}{l}+4.1(0.1) \\
\mathbf{p}<0.001\end{array}$ & 0.564 \\
\hline
\end{tabular}

$\mathrm{SBP}$, systolic blood pressure; DBP, diastolic blood pressure; MAP, mean arterial pressure; $P R$, pulse rate; $A U$, arbitrary units; $O N H$, optic nerve head.

*Data are presented as mean (SEM).

non-smokers. This response was significantly different between groups $(p=0.032$, ANOVA $)$. The response in choroidal blood to carbogen breathing was also significantly different between the two groups ( $p=0.049$, ANOVA) with an increase in blood flow in non-smokers $(p=0.048)$ and no change in smokers (fig 1). Fundus pulsation amplitude markedly increased after carbogen breathing in non-smokers $(\mathrm{p}<0.001 v$ baseline) but not in smokers and this difference was highly significant between the two groups (table 3; $\mathrm{p}<0.001$, ANOVA).

Red blood cell volume in the optic nerve head (fig 2) significantly decreased in smokers $(\mathrm{p}=0.01 v$ baseline), but not in non-smokers. This effect was, however, not significantly different between the two groups. Red blood cell velocity in response to carbogen breathing tended to decrease in both groups, but this effect was not significant. Accordingly, carbogen reduced optic nerve head blood flow in both groups versus baseline $(\mathrm{p}<0.01$ each), but no difference between groups was seen.

During administration of carbogen, retinal vessel diameters decreased in both groups to a comparable degree (fig 3).

As expected, both $\mathrm{pO}_{2}$ and $\mathrm{SaO}_{2}$ increased notably during carbogen breathing $(\mathrm{p}<0.001 v$ baseline for both). The increase of $\mathrm{pO}_{2}$ and $\mathrm{SaO}_{2}$ during carbogen breathing was, however, comparable between the two groups. The increase of $\mathrm{pCO}_{2}$ after carbogen breathing was significant in smokers $(\mathrm{p}<0.001 \quad v$ baseline $)$ and non-smokers $(\mathrm{p}<0.001 v$ baseline $)$, but not significant between the two groups. 

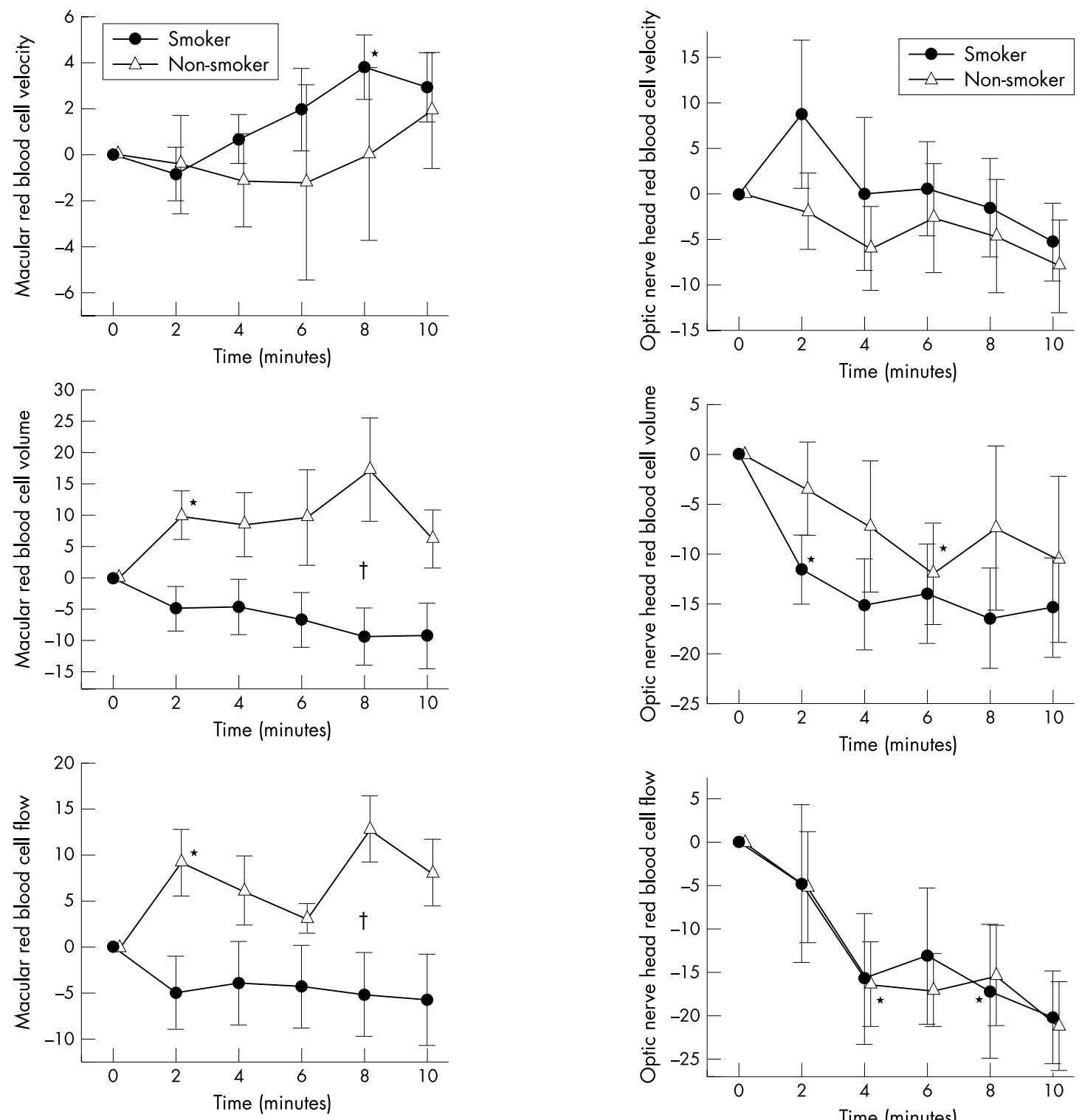

Figure 1 Choroidal red blood cell velocity, volume, and flow during carbogen breathing. Data are presented as mean (SEM) (smokers, $n=13$; non-smokers, $n=12)$. *Significant difference versus baseline ( $t$ test, post hoc testing). †Significant difference between smokers and nonsmokers (ANOVA).

\section{DISCUSSION}

The main finding of our study is that breathing of carbogen resulted in an increase of choroidal blood flow parameters in non-smoking volunteers, but not in smokers. No differences in response to carbogen breathing could be observed in systemic haemodynamics, optic nerve had blood flow, retinal vessel diameters, and blood gas values between both groups. This clearly indicates abnormal choroidal vascular responsiveness in smokers, whereas normal response patterns were seen in the optic nerve head and retinal vasculature.

Carbogen, a gas mixture containing 5\% $\mathrm{CO}_{2}$ and $95 \% \mathrm{O}_{2}$, has been used in humans for the treatment of central retinal artery occlusion. The amount of $\mathrm{CO}_{2}$ is assumed to prevent oxygen induced vasoconstriction and therefore maintain or even increase blood flow while providing the retina with increased oxygenation. ${ }^{18}$ The effects of carbogen on retinal circulation have already been investigated by several authors. A recent study of our group showed that carbogen breathing decreases retinal vessel diameter, retinal blood velocity, and

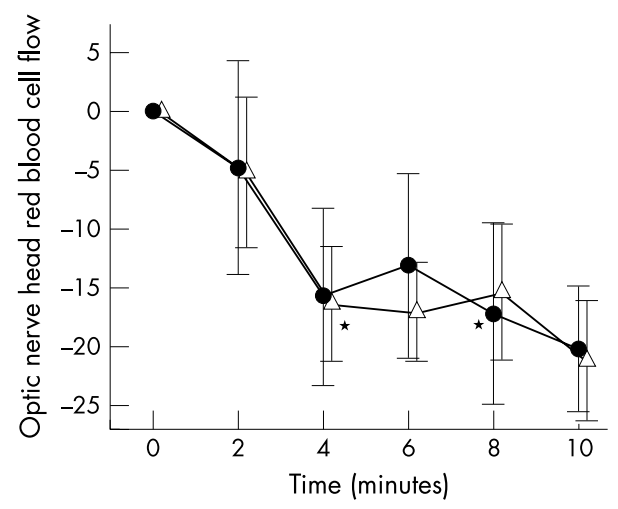

Figure 2 Optic nerve head red blood cell velocity, volume, and flow during carbogen breathing. Data are presented as mean (SEM) (smokers, $n=13$; non-smokers, $n=12$ ). *Significant difference versus baseline ( $t$ test, post hoc testing).

retinal blood flow. ${ }^{19}$ This is in accordance with another study also observing reduced retinal blood flow during carbogen breathing. ${ }^{20}$ In contrast, other groups found increased retinal perfusion, using the blue field entoptic technique and scanning laser ophthalmoscopy respectively. ${ }^{21}{ }^{22}$ Scanning laser ophthalmoloscopy, however, measures blood cell velocity only and the results cannot necessarily be extrapolated to blood flow. The blue field entoptic system assesses white blood cell flux, and potential differences between this method and retinal blood flow measurements with combined laser Doppler velocimetry and the retinal vessel analyser have been discussed in detail. ${ }^{23}$

It is well known that choroidal blood flow is strongly dependent on $\mathrm{pCO}_{2}$ and only slightly influenced by changes in $\mathrm{pO}_{2} \cdot{ }^{24}$ In humans, even pronounced changes in arterial oxygen tension have little impact on $\mathrm{CO}_{2}$ induced changes in subfoveal choroidal blood flow. ${ }^{24}$ This is in accordance with the findings of the present study in healthy subjects. In our study carbogen decreased optic nerve head blood flow in both 

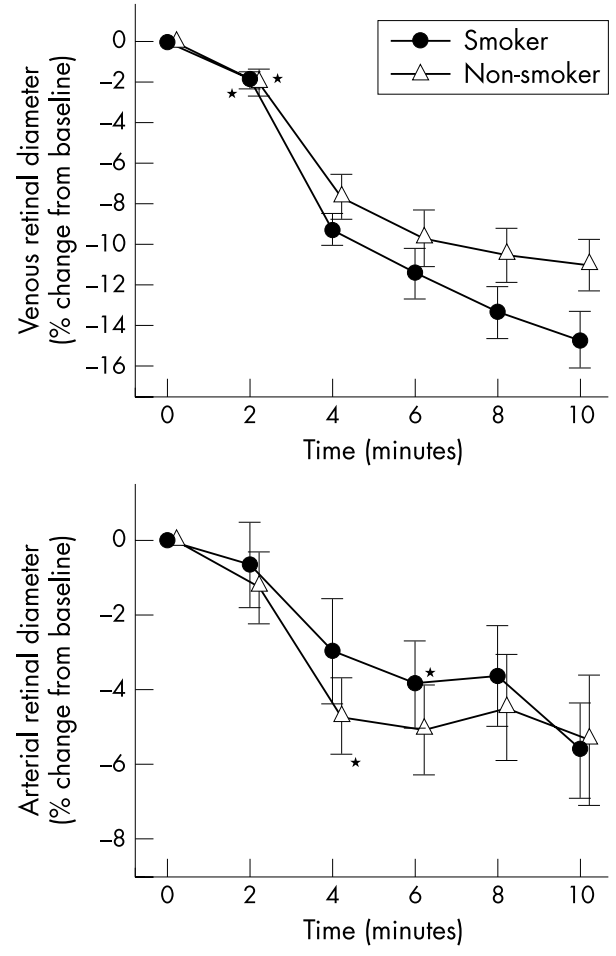

Figure 3 Retinal venous and arterial diameters during carbogen breathing. Data are presented as mean (SEM) (smokers, $n=13$; nonsmokers, $n=12$ ). *Significant difference versus baseline ( $t$ test, post hoc testing).

groups. Harris et al reported that optic nerve head blood flow is increased by hypercapnia by $28 \%$ in healthy subjects using the same technique as applied in the present study, ${ }^{25}$ whereas it is reduced by carbogen, as indicated by our results. Hence it may be speculated that the optic nerve head is more oxygen sensitive or less $\mathrm{CO}_{2}$ sensitive than the choroid. These findings may in part be explained by the fact that the optic nerve head is supplied by the posterior ciliary arteries as well as by the central retinal artery. Our findings in the optic nerve head are, however, in contrast to investigations of optic nerve head blood flow during carbogen breathing using the Heidelberg Retina Flowmeter, where carbogen increased optic nerve head blood flow. ${ }^{26}$ However, these previous results cannot be directly compared with our data, because laser Doppler flowmetry was applied over the whole optic disc area including visible larger vessels. With both techniques applied for the assessment of choroidal perfusion, an abnormal response to carbogen breathing was evident.

The mechanisms underlying $\mathrm{CO}_{2}$ induced vasodilation in the eye and the brain are not fully understood. Intra- and extracellular acidosis, ${ }^{24}$ adenosine, ${ }^{27}$ nitric oxide, ${ }^{28}$ ATP sensitive potassium channels, ${ }^{29}$ and the membrane calcium transport $^{30}$ are assumed to play a role in hypercapnia induced vasodilation in these vascular beds. Moreover, NO was shown to be involved in hypercapnia induced vasodilatation in the human choroid. ${ }^{31} \mathrm{NO}$ also appears to facilitate the action of other vasodilators during hypercapnia in the brain. ${ }^{32} \mathrm{~A}$ number of studies in humans tried to characterise which of these pathways are altered in chronic smokers. Smokers not only exhibited an impairment in nitric oxide mediated vasodilation, ${ }^{33}$ but also showed a defect in the vasoconstrictor response to angiotensine-I. ${ }^{34}$ Endothelial function is further altered by the free radical burden of cigarette smoke and a dysfunctional nitric oxide synthase III (NOS III) due to tetrahydrobiopterin (BH4) depletion in chronic smokers. ${ }^{35}$
Hence, one may hypothesise that abnormal endothelial function contributes to the results obtained for the choroid in the present study, although this hypothesis remains to be proved in future studies. In addition, future research is required to clarify why the response to hypercapnia in chronic smokers is altered in the choroid, but not in the optic disc or retina.

When discussing the results of the present study one needs to consider the limitations of each method. Laser Doppler flowmetry measures choroidal blood flow in relative units only, and absolute values are influenced by perfusion values as well as by the scattering properties of tissue. Therefore one must be careful to interpret the higher baseline laser Doppler flowmetry value in smokers as a proof of increasing basal choroidal blood flow in these subjects. This limitation does, however, not apply for relative changes as observed during carbogen breathing. With fundus pulsation amplitude measurements, one needs to consider that only the pulsatile component of choroidal blood flow is measured. However, consistency between laser Doppler flowmetry and fundus pulsation amplitude measurements was acceptable in the present study. We did not assess blood flow in the retina in this study and our data are limited to diameter information. In principle such measurements could have been done with bidirectional laser Doppler velocimetry; however, this study schedule was already extremely exhausting for the participating subjects.

In conclusion, the present study indicates abnormal vascular reactivity in smokers. These early haemodynamic changes may be related to the increased risk to smokers of developing ocular vascular disease. The specific mechanisms - either endothelial or humoral-that are foremost perturbed by chronic smoking, remain to be characterised.

\section{ACKNOWLEDGEMENTS}

Financial support by the Medizinisch-wissenschaftlicher Fonds des Bürgermeisters der Bundeshauptstadt Wien. (Project \#2190) is gratefully acknowledged.

\section{Authors' affiliations}

B Wimpissinger, H Resch, F Berisha, G Weigert, L Schmetterer, K Polak, Department of Clinical Pharmacology, Allgemeines Krankenhaus Wien, Vienna, Austria

L Schmetterer, Institute of Medical Physics, Allgemeines Krankenhaus Wien, Vienna, Austria

K Polak, Department of Ophthalmology, Allgemeines Krankenhaus Wien, Vienna, Austria

Correspondence to: K Polak, MD, Department of Clinical Pharmacology, Allgemeines Krankenhaus Wien, Währinger Gürtel 1820, A-1090 Vienna, Austria; Kaija.Polak@univie.ac.at

Accepted 17 November 2003

\section{REFERENCES}

1 Solberg $Y$, Rosner $M$, Belkin $M$. The association between cigarette smoking and ocular diseases. Surv Ophthalmol 1998:42:535-47.

2 Hara K. Effects of cigarette smoking on ocular circulation chronic effect on choroidal circulation. Nippon Ganka Gakkai Zasshi 1991;95:939-43.

3 Kaiser HJ, Schoetzau A, Flammer J. Blood flow velocity in the extraocular vessels in chronic smokers. Br J Ophthalmol 1997;81:133-5.

4 Steigerwalt RD Jr, Laurora G, Incandela L, et al. Ocular and orbital blood flow in cigarette smokers. Retina 2000;20:394-7.

5 Williamson TH, Lowe GD, Baxter GM. Influence of age, systemic blood pressure, smoking, and blood viscosity on orbital blood velocities. Br J Ophthalmol 1995;79:17-22.

6 Tamaki Y, Araie M, Nagahara M, et al. The acute effects of cigarette smoking on human optic nerve head and posterior fundus circulation in light smokers. Eye 2000; 14:67-72.

7 Rogers RL, Meyer JS, Shaw TG, et al. The effects of chronic cigarette smoking on cerebrovascular responsiveness to 5 per cent $\mathrm{CO}_{2}$ and 100 per cent $\mathrm{O}_{2}$ inhalation. J Am Geriatr Soc 1984;32:415-20. 
8 Haley NJ, Axelrad CM, Tilton KA. Validation of self-reported smoking behavior: biochemical analyses of cotinine and thiocyanate. Am J Public Health 1983;73:1204-7

9 Pomerleau CS, Carton SM, Lutzke ML, et al. Reliability of the Fagerstrom Tolerance Questionnaire and the Fagerstrom Test for Nicotine Dependence. Addict Behav 1994; 19:33-9.

10 Fagerstrom KO. Effects of a nicotine-enriched cigarette on nicotine titration, daily cigarette consumption, and levels of carbon monoxide, cotinine, and nicotine. Psychopharmacology 1982;77:164-7.

11 Riva CE, Cranstoun SD, Grunwald JE, et al. Choroidal blood flow in the foveal region of the human ocular fundus. Invest Ophthalmol Vis Sci 1994;35:4273-81.

12 Bonner RF, Nossal R. Principles of laser Doppler flowmetry. In: Shepard AP, Öberg PA, eds. Developments in Cardiovascular Medicine: Laser Doppler Blood Flowmetry. Boston: Kluwer Academic Publishers, 1980:73-92.

13 Schmetterer L, Lexer F, Unfried C, et al. Topical measurement of fundus pulsations. Opt Eng 1995;34:711-16.

14 Schmetterer L, Dallinger S, Findl O, et al. Noninvasive investigations of the normal ocular circulation in humans. Invest Ophthalmol Vis Sci 1998:39:1210-20.

15 Blum M, Bachmann K, Wintzer D, et al. Noninvasive measurement of the Bayliss effect in retinal autoregulation. Graefes Arch Clin Exp Ophthalmo 1999:237:296-300

16 Polak K, Dorner G, Kiss B, et al. Evaluation of the Zeiss retinal vessel analyser. Br J Ophthalmol 2000;84:1285-90

17 Jarvis MJ, Tunstall-Pedoe H, Feyerabend C, et al. Comparison of tests used to distinguish smokers from nonsmokers. Am J Public Health 1987;77: 1435-8.

18 Nielsen NV. Treatment of acute occlusion of the retinal arteries. Acta Ophthalmol (Copenh) 1979:57:1078-813.

19 Luksch A, Garhofer G, Imhof A, et al. Effect of inhalation of different mixtures of $\mathrm{O}_{2}$ and $\mathrm{CO}_{2}$ on retinal blood flow. Br J Ophthalmol 2002;86:1 143-7.

20 Pakola SJ, Grunwald JE. Effects of oxygen and carbon dioxide on human retinal circulation. Invest Ophthalmol Vis Sci 1993;34:2866-70.

21 Sponsel WE, DePaul KL, Zetlan SR. Retinal hemodynamic effects of carbon dioxide, hyperoxia, and mild hypoxia. Invest Ophthalmol Vis Sci 1992;33:1864-9.

22 Arend O, Harris A, Martin BJ, et al. Retinal blood velocities during carbogen breathing using scanning laser ophthalmoscopy. Acta Ophthalmol (Copenh) 1994;72:332-6.
23 Kiss B, Polska E, Dorner G, et al. Retinal blood flow during hyperoxia in humans revisited: concerted results using different measurement techniques. Microvasc Res 2002;64:75-85

24 Geiser MH, Riva CE, Dorner GT, et al. Response of choroidal blood flow in the foveal region to hyperoxia and hyperoxia-hypercapnia. Curr Eye Res 2000;21:669-76.

25 Harris A, Anderson DR, Pillunat L, et al. Laser Doppler flowmetry measurement of changes in human optic nerve head blood flow in response to blood gas perturbations. J Glaucoma 1996:5:258-65.

26 Haefliger IO, Lietz A, Griesser SM, et al. Modulation of Heidelberg Retinal Flowmeter parameter flow at the papilla of healthy subjects: effect of carbogen, oxygen, high intraocular pressure, and beta-blockers. Surv Ophthalmol 1999;43:S59-65.

27 Estevez AY, Phillis JW. Hypercapnia-induced increases in cerebral blood flow: roles of adenosine, nitric oxide and cortical arousal. Brain Res 1997;758: 1-8.

28 ladecola C, Zhang F. Nitric oxide-dependent and -independent components of cerebrovasodilation elicited by hypercapnia. Am J Physiol 1994; 266:R546-52.

29 Faraci FM, Breese KR, Heistad DD. Cerebral vasodilation during hypercapnia Role of glibenclamide-sensitive potassium channels and nitric oxide. Stroke 1994;25: 1679-83.

30 Azin AL. Oxygen, carbon dioxide and calcium control of the mechanisms of relaxation in the cerebral artery smooth musculature. Fiziol Zh SSSR Im I M Sechenova 1982;68:59-63.

31 Schmetterer L, Findl O, Strenn K, et al. Role of $\mathrm{NO}$ in the $\mathrm{O}_{2}$ and $\mathrm{CO}_{2}$ responsiveness of cerebral and ocular circulation in humans. Am J Physiol 1997:273:R2005-12.

32 ladecola $\mathrm{C}$, Zhang F. Permissive and obligatory roles of NO in cerebrovascular responses to hypercapnia and acetylcholine. Am J Physiol 1996;271:R990-1001.

33 McVeigh GE, Lemay L, Morgan D, et al. Effects of long-term cigarette smoking on endothelium-dependent responses in humans. Am J Cardiol 1996;78:668-72.

34 Butler $\mathbf{R}$, Morris $A D$, Struthers $A D$. Cigarette smoking in men and vascular responsiveness. Br J Clin Pharmacol 2001;52:145-9.

35 Heitzer T, Brockhoff C, Mayer B, et al. Tetrahydrobiopterin improves endothelium-dependent vasodilation in chronic smokers: evidence for a dysfunctional nitric oxide synthase. Circ Res 2000;86:E36-41. 